Canadian

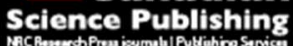

Canadian Journal of Microbiology Revue canadienne de de microbiologie

\title{
Mycobacterium smegmatis synthesizes in vitro androgens and estrogens from different steroid precursors.
}

\begin{tabular}{|c|c|}
\hline Journal: & Canadian Journal of Microbiology \\
\hline Manuscript ID: & cjm-2015-0025.R1 \\
\hline Manuscript Type: & Article \\
\hline Date Submitted by the Author: & 06-Apr-2015 \\
\hline Complete List of Authors: & $\begin{array}{l}\text { Dlugovitzky, Diana G.; Facultad de Ciencias M dicas } \\
\text { Fontela, María; Fac. Ciencias Médicas, Microbiology } \\
\text { Martinel- Lamas, Diego; Fac. Ciencias Médicas, Microbiology } \\
\text { Valdez, Ricardo; CINVESTAV del IPN, Fisiología, Biofísica y Neurociencias } \\
\text { Romano, Marta; CINVESTAV del IPN, Fisiología, Biofísica y Neurociencias }\end{array}$ \\
\hline Keyword: & $\begin{array}{l}\text { Mycobacterium , Mycobacterium smegmatis, Steroid synthesis, Androgens, } \\
\text { Estrogens }\end{array}$ \\
\hline
\end{tabular}

SCHOLARONE $^{\text {It }}$

Manuscripts 
$3 \quad$ Mycobacterium smegmatis synthesizes in vitro androgens and estrogens from 4 different steroid precursors.

5

6

101 Sección Inmunología. Cátedra de Microbiología, Facultad de Ciencias Médicas. Universidad 11 Nacional de Rosario. Argentina.

12 2. Departamento de Fisiología, Biofísica y Neurociencias, CINVESTAV del I.P.N., México DF. , 13 México

14

15

16 Corresponding autor:

17

18

19 


\section{Abstract}

Fast-growing mycobacteria as Mycobacterium sp and smegmatis degrade natural sterols. They are a model to study tuberculosis. Interestingly, Mycobacterium smegmatis (M. smegmatis) have been found in river effluents derived from paper production and therefore it would important to gain further insight in their capacity to synthesize steroids that are potential endocrine disruptors affecting the development and reproduction of fishes. To our knowledge, the capacity of $M$. smegmatis to synthesize estrogens and even testosterone had not been reported. Therefore, the objective of this study was to investigate the capacity of $M$. smegmatis to synthesize in vitro testosterone and estrogens from tritiated precursors and to investigate the metabolic pathways involved. Results obtained by thin layer chromatography showed that ${ }^{3} \mathrm{H}$-progesterone was transformed to $17 \mathrm{OH}$-progesterone, androstenedione, testosterone, estrone and estradiol after 6, 12 or $24 \mathrm{~h}$ of incubation. ${ }^{3} \mathrm{H}$-androstenedione was transformed to testosterone and estrogens mainly estrone, and ${ }^{3} \mathrm{H}$-testosterone to estrone and androstenedione. Incubation with ${ }^{3} \mathrm{H}-$ dehydroepiandrosterone rendered androstendiol, testosterone and estrogens. The ability of transforming less potent sex steroids as androstenedione and estrone to other more active like testosterone and estradiol or viceversa suggests that M.smegmatis influence the amount of self synthesized strong androgens and estrogens and can transform those found in the environment.

Key Words: Mycobacterium, Mycobacterium smegmatis, Steroid synthesis, Androgens, Estrogens : 
The mycobacteria $(M)$ include a number of human pathogens of worldwide importance, such as Mycobacterium tuberculosis (MTB), Mycobacterium leprae, and Mycobacterium avium. ycobacterium tuberculosis is still a major killer and constitutes a serious menace to global health. A fast growing member of this genus, Mycobacteriun smegmatis ( $M$. smeg) is another interesting microorganism. Despite the evolutionary differences between M. smegmatis and MTB, the first one can produce the MTB ESAT- 6 and CFP-10 proteins, suggesting that substrate recognition is also conserved between the two species. Several authors reported comparative studies of different genes as $w h m D e g$, an essential gene in $M$. smeg, involved in cell division while its counterpart present in $M T B$, whiB2, is functionally equivalent. The existence of genes that share significant sequence homology in coding and non-coding DNA in both species MTB and M. smegmatis had been also demonstrated (Raghunand and Bishai, 2006; Rajagopalan et al. 2005; Goehring and Beckwith, 2005). Therefore, M. smegmatis is considered a strong system to study several products, like the multicomponent Snm secretory machine (a significant determinant of MTB virulence) and to appreciate the role of this conserved system in mycobacterial biology (Converse and Cox, 2005).

On the other hand, studies had demonstrated that fast-growing mycobacteria degrade natural sterols and use them as a source of carbon and energy. A number of bacteria have been reported to accumulate some sterols and metabolize them to intermediates such as 4-androstene-3,17-dione and 1,4-androstadiene-3,17-dione (Mahato and Garai, 1997, Martin, 1977, Szentirmai, 1990, Brzostek, et al. 2005,). These intermediates could be useful in industry as precursors for the production of steroid drugs and hormones (Sedlaczek, 1988). The capacity of some microorganisms, represented by Mycobacterium, Corynebacterium and Arthrobacter to make use of sterols as sole sources of carbon and energy, was described years ago by Soehngen (1913). $17 \beta$-hydroxysteroid dehydrogenase (17 $\beta$-HSD) is a crucial enzyme that catalyzes the reversible reduction of 17-keto group of androgens and estrogens in vertebrates and invertebrates. To our knowledge, 14 types of mammalian 17 $\beta$-HSD have been described or annotated in public databases, but only 12 have orthologues in humans (Lukacik et al. 2006). It has been reported the isolation and characterization of this enzyme in several species of bacteria such as Alcaligenes $s p$ (Payne and Talalay, 1985) and Comamonass testosteroni (Pseudomonas testosterone) (Groman and Engel, 1977), Cylindrocarpon radicicola (Itagaki and Iwaya, 1988) as well as fungi (Lanisnik et al. 1999). This enzyme was detected also by differential centrifugation in Pseudomonas testosterone as membrane-bounded and cytosol soluble forms (Lefebre et al. 1979). Additionally, two activities of reductive 1-ene-steroid reductase and 17-keto steroid reductase were observed in 
Mycobacterium. sp (Goren et al 2002). Two 17OH-HSDs from a mutant Mycobacterium sp have been also isolated and purified. One of them is responsible for the bidirectional redox oxygen function at $\mathrm{C} 17$, while the other specifically catalyzes the oxidation of 17-beta-steroids such as testosterone and dihydrotestosterone (Egorova et al. $2002 \mathrm{a}$ and b).

Sterol synthesis by the saprofitic microorganism M.smegmatis was reported using ${ }^{14} \mathrm{C}$ radiolabelled mevalonic acid and incorporation to into C4-desmethyl sterol co migrating with authentic cholesterol on TLC (Lamb et al, 1998). Microbial transformation of 3-hydroxy-5,6cyclopropanocholestanes into 17-keto steroids, between them androstenedione (A4), had been reported in Mycobacterium sp (Yan et al. 2000) and in M.smegmatis (Naghib et al. 2002). Jenkins et al (2004) had demonstrated that M. smegmatis incubated in the presence of progesterone produced $17 \alpha$-hydroxyprogesterone (17 $\alpha$-OHP), androstenedione (A4) and androstadienedione (ADD). Given M. smegmatis biological characteristics and for being safety for laboratory use, this strain had been used as a model for many MTB studies.

Interestingly, M. smegmatis have been found in river effluents derived from paper production (Jenkins et al. 2003; Jenkins et al. 2004) and it has been previously reported the presence of progesterone and androstenedione in the water column and bottom sediments of the Fenholloway River, Taylor County, Florida which receives paper mill effluent and contains masculinized female mosquitofish, Gambusia Holbrooki. It was hypothesized that plant sterols (e.g., $\beta$ sitosterol) derived from the pulping of pine trees are transformed by bacteria into progesterone and subsequently into $17 \alpha-\mathrm{OHP}$, androstenedione, and androstadienedione (ADD) by degradation of phytosterols (Roy et al. 1991; Durham et al. 2002; Jenkins et al. 2003). In a later study, it was demonstrated that these same androgens can be produced in vitro by M. smegmatis (Jenkins 2004). Therefore it would important to further study their capacity to synthesize steroids that may work as endocrine disruptors affecting the development and reproduction of fishes (Segner et al. 2003; Brion et al. 2004; Fenske et al. 2005; Waye and Trudeau, 2011).

To our knowledge, the capacity of $M$. smegmatis to synthesize estrogens and even testosterone had not been reported. Although several authors have described microorganisms capable of degrading cholesterol, sterols and steroids, the routes of microbial transformation/degradation of these compounds, some of which produce aromatic intermediates are not known in detail. Understanding of these routes is of great interest to both the industry and the environment as this would allow manipulation through genetic engineering and new intermediaries for metabolic / synthetic steroid precursors as well as important microorganisms used for purification processes of the water. 
127 Therefore, the objective of the present study was to get deeper insight into the capacity of $M$. 128 smegmatis to synthesize in vitro testosterone and estrogens from different precursors, and 129 simultaneously to investigate the metabolic pathways involved in the steroid synthesis or 130 degradation produced by these microorganisms.

$131 \quad$ Materials and Methods

132 Mycobacterium smegmatis culture:

133 Mycobacterium smegmatis PTCC 1307 (CIP 73.26), provided by the National Institute of 134 Respiratories Diseases, Santa Fe, Argentine, Dr. Emilio Coni, was used as a microbial agent, from 135 a culture of M. smegmatis developed in Middlebrook 7H10 media (Sigma-Aldrich Chemical Co,

136 St. Louis, MO, USA). The bacteria were seeded in Middlebrook 7H9 liquid medium purchased in 137 the same company.

138 Mycobacterium smegmatis was grown to mid-log phase (optical density at $600 \mathrm{~nm}$ [OD 600], 0.6 139 to 0.8 ) in $7 \mathrm{H} 9$ media supplemented with $0.05 \%$ Tween 80 (Sigma-Aldrich Chemical Co, St. 140 Louis, MO, USA).

141 Bacilli were grown in this medium for $48 \mathrm{~h}$ until a concentration of $1.5 \times 10^{9}$ bacteria $/ \mathrm{ml}$ was 142 reached. Mycobacteria presence was confirmed by Ziehl-Neelsen stain. To detect any other type 143 of bacterial contamination in liquid culture media containing M. smegmatis $100 \mu \mathrm{L}$ of each of the 144 jars were seeded on a $5 \%$ blood agar plate, and incubated for $24 \mathrm{~h}$ at $28^{\circ} \mathrm{C}$.

145 Evaluation of mycobacteria concentration

146 To determine the concentration of mycobacteria the McFarland nephelometer was used. Serial 147 dilutions of the sample were seeded in Middlebroock medium and subsequently counted up of $1487 \mathrm{H} 10$ plates grown at $28^{\circ} \mathrm{C}$ was performed, and the $\mathrm{OD}$ data (at $600 \mathrm{~nm}$ ) were obtained by the 149 spectrophotometer measures.

\section{$150 \quad$ Precursor transformation}

151 The bacteria were developed in Middlebrook $7 \mathrm{H} 9$ medium for $48 \mathrm{~h}$ with stirring until a 152 concentration of $1.5 \times 10^{9}$ bacteria $/ \mathrm{ml}$. was reached. The culture was fractionated in $1 \mathrm{ml}$ aliquots. 153 Bacilli were cultured for 6,12 or $24 \mathrm{~h}$ with various tritiated precursors separately in quadruplicate. $154 \quad{ }^{3} \mathrm{H}$-Progesterone, ${ }^{3} \mathrm{H}$-Dehydroespiandrosterone ${ }^{3} \mathrm{H}$-Androstenedione, ${ }^{3} \mathrm{H}$-testosterone $\left({ }^{3} \mathrm{H}-\mathrm{P} 4,{ }^{3} \mathrm{H}-\right.$ 155 DHEA, ${ }^{3} \mathrm{H}-\mathrm{A} 4$ and ${ }^{3} \mathrm{H}-\mathrm{T}$, respectively), at a concentration of 50,000 counts/ml were used as 156 precursors. Simultaneously, tubes containing culture medium without bacteria were incubated 157 with the tritiated precursors (control tubes, blanks). After incubation time, bacteria were separated 158 by centrifugation at $1200 \mathrm{~g}$ for $15 \mathrm{~min}$, resuspended in PBS and centrifuged again. The washing 
159

160

161

162

163

164

165

166

167

168

169

170

171

172

173

174

175

176

177

178

179

180

181

182

183

184

185

186

187

188

189

190

was repeated two times and finally the pellet was frozen until extraction. The bacteria culture media was reserved until steroid extraction was done.

\section{Steroids extraction}

The bacteria culture media was poured to glass tubes and steroids were ether-extracted with diethyl ether to a $1: 5$ ratio, in a bath at $38-40^{\circ} \mathrm{C}$. The mixture was stirred by vortex for 1 minute, and left to stand for 10 minutes. The vials were placed in a mixture of dry ice-acetone $\left(-70^{\circ} \mathrm{C}\right)$ for 15 minutes to freeze the aqueous phase and thereafter the ether phase containing the steroids was decanted and dried under $\mathrm{N}_{2}$ gas. The samples were stored until steroids were submitted to thin layer cromatography (TLC) as described in Valdez et al. (2006).

\section{Thin Layer cromatography}

The authentic standards used were progesterone, 17-OH-Progesterone (17OH- $\left.\mathrm{P}_{5}\right)$, androstenedione $\left(\mathrm{A}_{4}\right)$, dehydroespiandrosterone (DHEA), androstenediol (Adiol), testosterone $\left(\mathrm{T}_{4}\right)$, estrone $\left(\mathrm{E}_{1}\right)$ and estradiol $\left(\mathrm{E}_{2}\right)$ (Steraloids Wilton $\left.\mathrm{NH}\right)$.

The extracted steroids were solubilized in $100 \mu \mathrm{L}$ of absolute ethanol and $20 \mu \mathrm{L}$ were seeded in Silica gel $60 \mathrm{~F}_{254}$ pre-coated sheet plates (Merck, Darmstadt, Germany) together with the authentic standards. To perform the chromatographic runs the system dichloromethane: ethyl acetate $(8: 2 \mathrm{v} / \mathrm{v})$ was used.

The standards were detected on the plates by UV light and 10\% sulfuric acid followed by heat. The region was used for standard grid plate. Subsequently, the corresponding samples region was cut, and placed in vials with $5 \mathrm{~mL}$ of scintillation liquid. Finally, the radioactivity was quantified in a counter for Beta emissions. The results were expressed as percentage transformation of each identified metabolite from the corresponding tritiated precursor.

\section{Statistical analysis}

Statistical analysis was performed using Prism version 4. 2003 (GraphPad Software Inc.). Data are presented as means \pm SE. Probability values of $\mathrm{P}<0.05$ were considered to be significant. Kruskal-Wallis followed by Dunn's multiple comparison post-test, were used to investigate statistical differences between groups. The experiments were performed by quatriplicate.

\section{$\underline{\text { RESULTS }}$}

\section{Transformation of triated precursors}

Figures 1, 2, 3 and 4 show the graphs which depict the percentage of transformation of the different tritiated precursors to steroid metabolites at 6,12 or $24 \mathrm{~h}$ of incubation $(\mathrm{A}, \mathrm{B}$, and $\mathrm{C}$ 
191 respectively). Different metabolite percentages of transformation were observed, depending on

192 the precursor from which they proceeded, as well as of the time of incubation.

193 Figure 1 A show that ${ }^{3} \mathrm{H}-\mathrm{Progesterone}\left({ }^{3} \mathrm{H}-\mathrm{P} 4\right)$ was transformed to $17 \mathrm{OH}-\mathrm{P} 4, \mathrm{~A} 4, \mathrm{~T}, \mathrm{E} 1$ and E2 after $6 \mathrm{~h}$ of incubation. The same metabolites were found at 12 and $24 \mathrm{~h}$ of culture, but their relative proportions changed (Fig.1 B and C). Tritiated testosterone significantly increased along time in culture $(6 \mathrm{~h}$ vs $24 \mathrm{~h} \mathrm{P}<0.05)$ while $17 \mathrm{OH}-\mathrm{P} 4$ decreased $(6 \mathrm{~h}$ vs $24 \mathrm{~h} \mathrm{P}<0.01)$. Transformation of the precursors to E1 and E2 was also observed at 12 and $24 \mathrm{~h}$, however their transformation decreased with time in culture (Fig. $1 \mathrm{~A}$ and $\mathrm{B}, 6 \mathrm{~h}$ vs $12 \mathrm{~h} \mathrm{P}<0.001$ ).

Incubation of cells with $3 \mathrm{H}-\mathrm{A} 4$ resulted in transformation to testosterone and to a small percentage of E1 and E2 after $6 \mathrm{~h}$ of culture (Fig. 2A). After $24 \mathrm{~h}$ of culture, testosterone synthesis slightly increased ( $6 \mathrm{~h}$ vs $24 \mathrm{~h} \mathrm{P}<0.05$ ), but the most striking change was that of E1 synthesis that reached values similar to those of testosterone in the course of the experiment $(6 \mathrm{~h}$ vs $12 \mathrm{~h}$ $\mathrm{P}<0.05,12$ vs 24 h non significant) while E2 almost disappeared (Fig. 2 B and C).

Tritiated testosterone was transformed to A4, E1 and E2 after six hours of culture (Fig. 3A). Estrone as well as E2 synthesis augmented after $12 \mathrm{~h}$ (E1, $6 \mathrm{~h}$ vs $24 \mathrm{P}<0.05$; E2, $12 \mathrm{~h}$ vs $24 \mathrm{~h}$ $\mathrm{P}<0.05)$ while androstendione decreased at $24 \mathrm{~h}$ of culture ( $6 \mathrm{~h}$ vs $24 \mathrm{~h} \mathrm{P}<0.05$, Fig. $3 \mathrm{~B}$ and $\mathrm{C})$.

Figure 4 shows the transformation of tritiated DHEA to its metabolites. The synthesis of Adiol, testosterone and estrogens was found after six hours of culture (Fig. 4A). No significant changes along time of culture were observed in the case of testosterone and estradiol, but Adiol had a trend to increase at $24 \mathrm{~h}$ (Fig $4 \mathrm{~B}$ and C). The synthesis of estrone was found to be increased when 12

\section{$\underline{\text { DISCUSSION }}$}

In this study we have explored the capacity of Mycobacterium smegmatis to transform steroid hormone precursors to sex steroids. The results showed that $M$. smegmatis can use both the $\Delta 4$ and the $\Delta 5$ steroidogenic pathways to achieve the sex steroid synthesis. The increase of the final products of the pathway and the decrease of the precursors that act as substrates of the reaction suggests the existence of steroidogenic enzymes that are required for these metabolic transformations. Such enzymes would be homologous to the steroidogenic enzymes found in vertebrates and invertebrates, and even in some microbes.

221 The presence of androgens and estrogens after incubation of M. smegmatis with tritiated progesterone showed that this microorganism could synthesize metabolites through the $\Delta 4$ steroidogenic pathway. The synthesis of $17 \alpha-\mathrm{HO}-$ progesterone, A4 and ADD by M. smegmatis 
was previously shown by Jenkins et al. (2004). In the present study we found that this microbe also synthesize testosterone and estrogens, suggesting that $M$. smegmatis can aromatize androgens to yield estrogens through the activity of a P-450 aromatase similar to that found in vertebrates and some invertebrates. The estrogen yields found here also raised concern about the presence of estrogens in rivers receiving paper mill effluents.

The estrogen synthesis obtained after incubation of $M$. smegmatis with A4 or $\mathrm{T}$ further demonstrate their capacity to synthesize these hormones. Interestingly, incubation in the presence of $\mathrm{T}$ resulted in an important transformation to A4 suggesting that a bidirectional pathway is present in M. smegmatis. The transformation of T to A4 could be a defense mechanism to degrade potent androgens to compounds with a lesser androgenic capacity. As shown at 12 and $24 \mathrm{~h}$ of incubation with tritiated A4, E1 increased while A4 decreased suggesting that the latter steroid was being actively transformed to E1. However transformation of T to E2 and thereafter to E1 is another possibility that should be considered. In general, E1 was the predominant estrogen synthesized by $M$. smegmatis suggesting again a defense mechanism to degrade potent estrogens to compounds with lesser activity.

Androgens and estrogens were also detected in this study when ${ }^{3} \mathrm{H}$-DHEA was the precursor. The synthesis of A4 from DHEA observed in this study after $6 \mathrm{~h}$ of incubation requires the activity of a $3 \beta$-hydroxysteroid dehydrogenase. The intracellular presence of this enzyme have been described in a mutant strain of Mycobacterium sp (Egorova et al. 2005) and an extracellular 3 $\beta$ hydroxysteroid oxydase form was found in Mycobacterium vaccae by Nicolayeva et al. (2004). The synthesis of Adiol found in our study also suggests the presence of a $17 \beta-\mathrm{OH}$-steroid dehydrogenase like in M. smegmatis. Afterward, experiments using DHEA as the precursor strongly suggest that these microorganisms can connect $\Delta 5$ and $\Delta 4$ steroidogenic pathways.

The ability to transform weak sex steroids as androstenedione and estrone to more active ones like testosterone and estradiol or viceversa, suggests that M.smegmatis has the capacity to modulate the amount of strong androgens and estrogens manufactured by themselves and / or those found in the environment.

The results of this investigation strongly suggest the existence in M.smegmatis of steroidogenic pathways similar to those already described for vertebrates and some invertebrates, such as $\Delta 4$ and $\Delta 5$ steroidogenic pathways, in which, starting from cholesterol or other steroid precursors, intermediates are converted in their final metabolites.

\section{REFERENCES}


258 Brion, F., Tyler, C.R., Palazzi, X., Laillet, B., Porcher, J.M., Garric, J., Flammarion, P.. 2004. 259 Impacts of $17 \beta$-estradiol, including relevant concentrations, on reproduction after exposure during 260 embryo-larval-juvenile-and adult-life stages in zebrafish (Danio rerio). Aquat Toxicol 68:193261217.

262

Brzostek, A., Śliwiński, T., Rumijowska-Galewicz. A., Korycka-Machała, M., Dziadek, J. 2005. Identification and targeted disruption of the gene encoding the main 3-ketosteroid dehydrogenase in Mycobacterium smegmatis. Microbiology 151(7):2393-2402.

266

Converse, S.E. and Cox, J.S. 2005. A Protein Secretion Pathway Critical for Mycobacterium 268 tuberculosis Virulence is Conserved and Functional in Mycobacterium smegmatis. J. Bacteriol., 269 187(4):1238-1245.

270

Durhan, E.J., Lambright, C., Wilson, V., Butterworth, B.C., Kuehl, D.W., Orlando, E.F., et al. 272 2002. Evaluation of androstenedione as an androgenic component of river water downstream of a pulp and paper mill effluent. Environ. Toxicol. Chem. 21:1973-1976.

Egorova, O., Nikolayeva, V., Donova, M. 2002 a. 17-Hydroxyxteroid dehydrogenase of 277

Egorova, O.V., Gulevskaya, S.A., Puntus, I.F., Filonov, A.E. and Donova, M.V. 2002 b. 280 Production of androstenedione using mutants of Mycobacterium sp. J of Chem Thechnol Biotechnol, 77:141-147.

281

Egorova, O.V., Nikiloyev,a V.M., Suzina, N.E., Donova, M.V. 2005. Localization of 17ß283 hydroxysteroid dehydrogenase in Mycobacterium sp. VKM Ac-1815D mutant strain. J Steroid 284 Biochem Mol Biol, 94:519-525. 
Fenske, M., Maack Schäfers, C., Segner, H. 2005. An environmentally relevant concentration of estrogen induces arrest of male gonad development in zebrafish, Danio rerio. Environ. Toxicol. Chem. 2005, 24:1088-1098.

Goehring, N.W. and Beckwith, J. 2005. Diverse paths to midcell: assembly of the bacterial cell division machinery. Curr Biol 15:514-526.

Goren, T., Harnik, M., Rimon, S., Ahoranowitz, Y. 2002. 1-Ene-steroid reductase of Mycobacterium sp producing androstenedione. J Chem Technol Biotech, 77:273-279.

Groman, E.V., Enge,1 L.L. 1977. Hydroxysteroid dehydrogenase of Pseudomonas testosterone: Separation of a $17 \beta$-hydroxysteroid dehydrogenase from the 3(17) $\beta$-hydroxysteroid dehydrogenase and comparison of the two enzymes. Biochimica et Biophysica Acta (BBA) Enzymology, 1977, 485: 249-254

Itagaki, E., Iwaya, T.1988. Purification and characterization of $17 \beta$-hydroxysteroi dehydrogenase from Cylindrocarpon radicicola. J. Biochem 103:1039-1044.

Jenkins, R.L., Wilson, E.M, Angus, R.A., Howel, W.M., Kirk, M. 2003. Androstenedione and Progesterone in the Sediment of a River Receiving Paper Mill Effluent. Oxford J Life Sci Med Toxicol Sci 1:53-59.

Jenkins, R.L., Wilson, E.M., Angus, R.A., Howell, W.M., Kirk, M., Moore, R., Nance, M., Brown, A. 2004. Production of Androgens by Microbial Transformation of Progesterone in Vitro: A Model for Androgen Production in Rivers Receiving Paper Mill Effluent. Environ Health Perspect 112(15):1508-1511.

Lanisnik Rizner, T., Moeller, G., Thole, H., Akelj-Mavri, M., Adamski, J. 1999. A novel 17 ßhydroxysteroid dehydrogenase in the fungus Cochliobolus lunatus : new insight into evolution of steroid hormone signalling. Biochem J 337: 425-431. 
317 Lamb, D.C., Kelly, D.E., Manning, N.J., Kelly, S.L. 1979. A sterol biosynthetic pathway in 318 Mycobacterium- FEBS Letters 437:142-144.

Lefebre, Y., Schultz, R., Groman, E., Watanabe, M. 1979. Localization of $3 \beta$ and 17 322

Mahato, S.B., Garai, S. 1997. Advances in microbial steroid biotransformation. Steroids 62:332345.

Lukacik, P., Kavanagh, K.L., Oppermann, U., 2006. Structure and function of human 17bhydroxysteroid dehydrogenases. Mol. Cell. Endocrinol. 248, 61-71.

Martin, C.K. Microbial cleavage of sterol side chains. 1977. Adv Appl Microbiol 22:29-58.

Naghibi F., Tabatabai Yazd, M., Sahebgharani, M., Noori Daloii, M.R. 2002. Microbial transformation of cholesterol. Journal of Sciences, Islamic Republic of Iran, 13(2):103-106.

333

334 335 336 337

Raghunand, T.R. and Bishai, W.R. 2006. Mycobacterium smegmatis whmD and its homologue 345

Nikolayeva VM, Egorova OV, Dovbnya DV, Donova MV. 2004. Extracellular 3 beta hydroxysteroid oxidase of Mycobacterium vaccae VKM Ac-1815D. J Steroid Biochem Mol Biol. 91(1-2):79-85.

Payne, D. W., Talalay P. 1985. Isolation of novel microbial 3 alpha-, 3 beta-, and 17 betahydroxysteroid dehydrogenases. Purification, characterization, and analytical applications of a 17 beta-hydroxysteroid dehydrogenase from an Alcaligenes sp. Journal of Biological Chemistry, 260, 13648-13655. Mycobacterium tuberculosis whiB2 are functionally equivalent. Microbiol, 152: 2735-2747. 
346

347

348

349

350

351

352

353

354

355

356

357

358

359

360

361

362

363

364

365

366

367

368

369

370

371

372

373

374

375

Rajagopalan, M., Maloney, E., Dziadek, J., Poplawska, M., Lofton, H., Chauhan, A., Madiraju, M.V. 2005. Genetic evidence that mycobacterial FtsZ and FtsW proteins interact, and colocalize to the division site in Mycobacterium smegmatis. FEMS Microbiol Lett, 250:9-17.

Roy, P.K., Khan, A.W., Basu, S.K.1991. Transformation of sitosterol to androsta-1,4-diene-3,17dione by immobilized Mycobacterium cells. Indian J Biochem Biophysiol 28:150-154.

Segner, H., Caroll, K., Fenske, M., Janssen, C.R., Maack, G., Pascoe, D., Schäfers, C., et al. 2003. Identification of endocrine-disrupting effects in aqua tic vertebrates and invertebrates: report from the European IDEA project. Ecotoxicol Environ Saf. 54:302-314.

Sedlaczek, L. 1988. Biotransformation of steroids. Crit. Rev. Biotechnol. 7:187-236.

Söhngen NL.1913. Zentr. Bakteriol. Parasitenk., Abt II, 37, 595.

Szentirmai, A. 1990. Microbial physiology of side chain degradation of sterols. J. Ind. Microbiol.6:101-115.

Valdez, R.A., Jiménez, A.L., Cartas, A.L., Gómez, Y., Romano, M.C. 2006. Taenia solium cysticerci synthezise androgens and estrogens in vitro. Parasitol Res 98:472-276.

Waye, A., Trudeau, V.L. 2011. Neuroendocrine disruption: More than hormones are upset. J. Toxicol. Environ. Health. B Crit. Rev. 14: 270-291

Yan, J.L., Lee, S.S., Wang, K.C. 2000. Microbial transformation of 3-hydroxy-5,6cyclopropanochlestanes, and alternative route to 6-methysteroids. Steroids 65: 863-70. 
377 Figure 1. Tranformation of ${ }^{3} \mathrm{H}$-progesterone to sex steroid metabolites by $M$. smeg after different 378 periods of incubation with the precursor. The bacteria were incubated for 6 (A), 12 (B) or 24 (C) 379 hours in the presence of tritiated progesterone. Data show the mean $\pm \mathrm{SE}$

380 Figure 2. Metabolism of ${ }^{3} \mathrm{H}$-androstenedione to its metabolites by M. Smeg. Tritiated 381 androstenedione, estrone and estradiol were found after 6 (A), 12 (B) or 24 (C) hours of 382 incubation. Data show the mean $\pm \mathrm{SE}$.

383 Figure 3. Transformation of ${ }^{3} \mathrm{H}$-testosterone to steroid metabolites by $M$. Smeg. The 384 microorganisms were incubated for 6 (A), 12 (B) or 24 (C) hours in the presence of the tritiated 385 precursor. Data show the mean $\pm \mathrm{SE}$.

387 Figure 4. Metabolism of ${ }^{3}$ H-DHEA to its metabolites by M. Smeg. Tritiated androgens and 388 estrogens were found after 6 (A), 12 (B) or 24 (C) hours of incubation with the precursor. Data 389 show the mean \pm SE. 
Figure 1

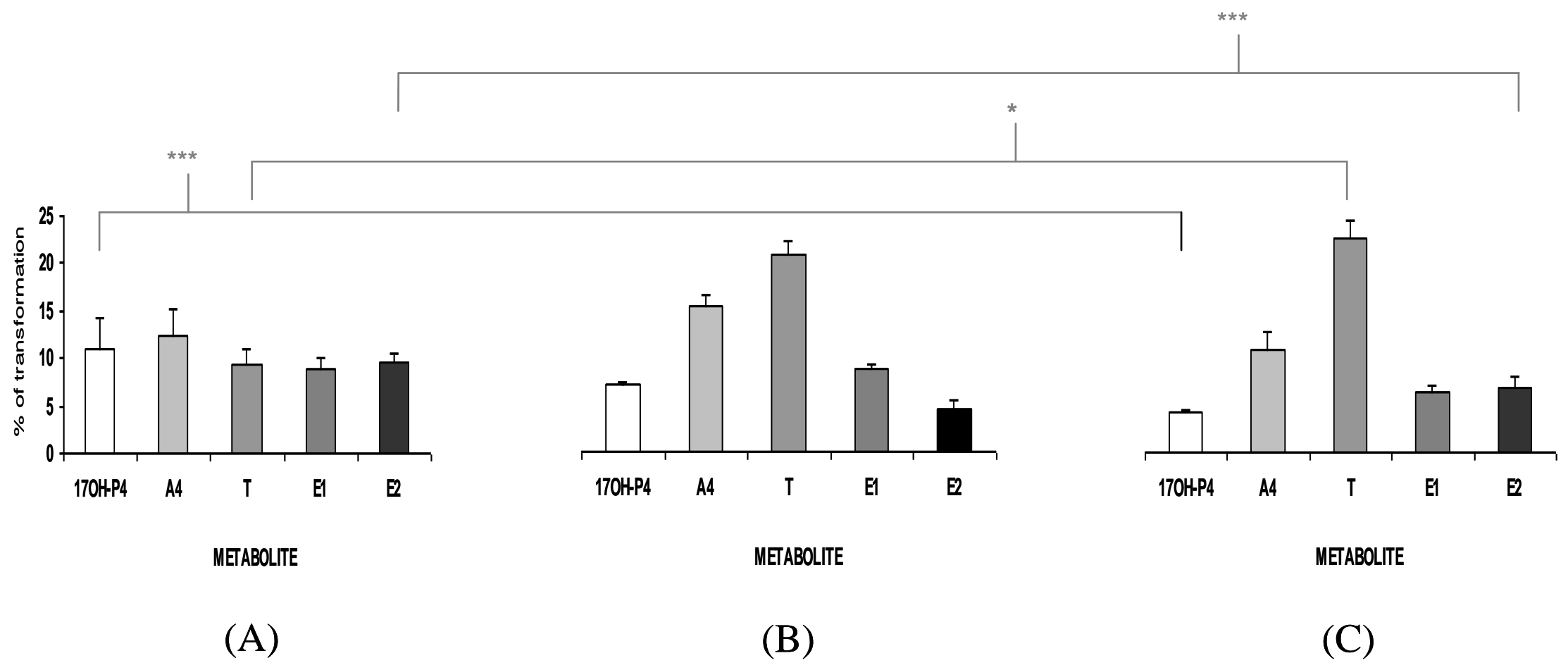




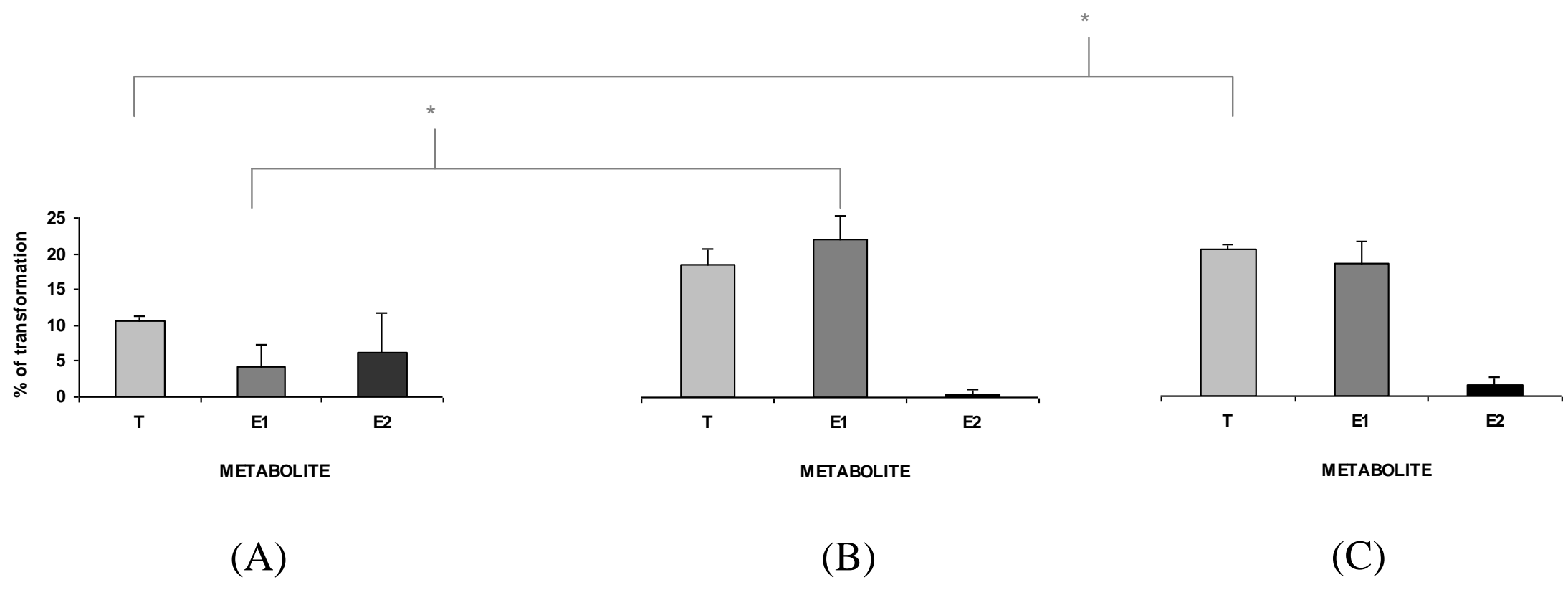


Figure 3

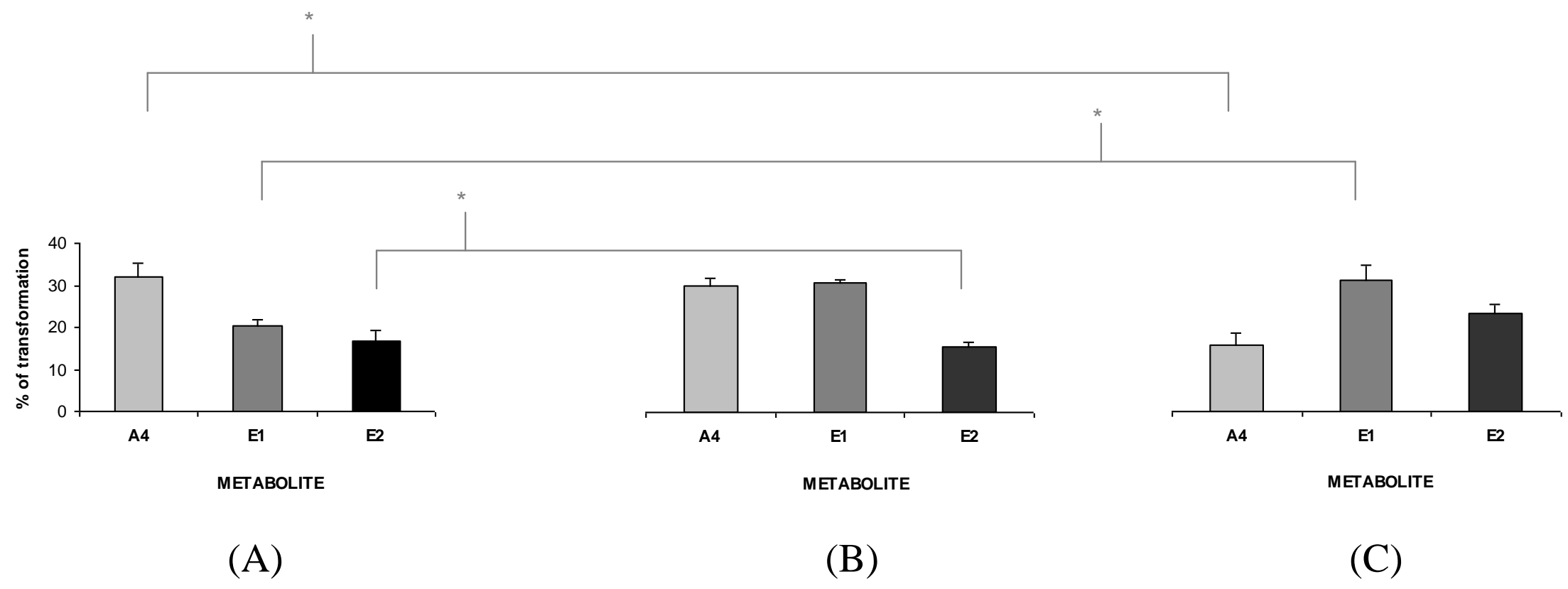




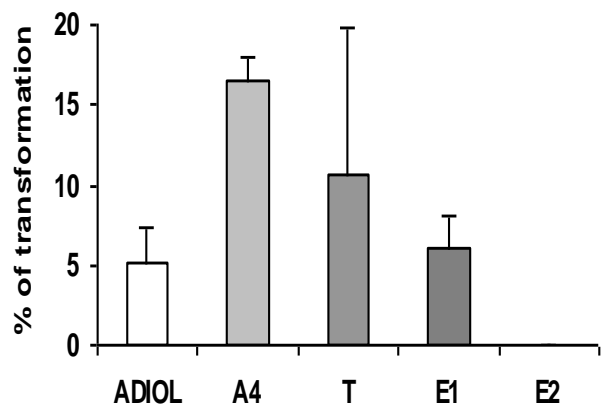

METABOLITE

(A)

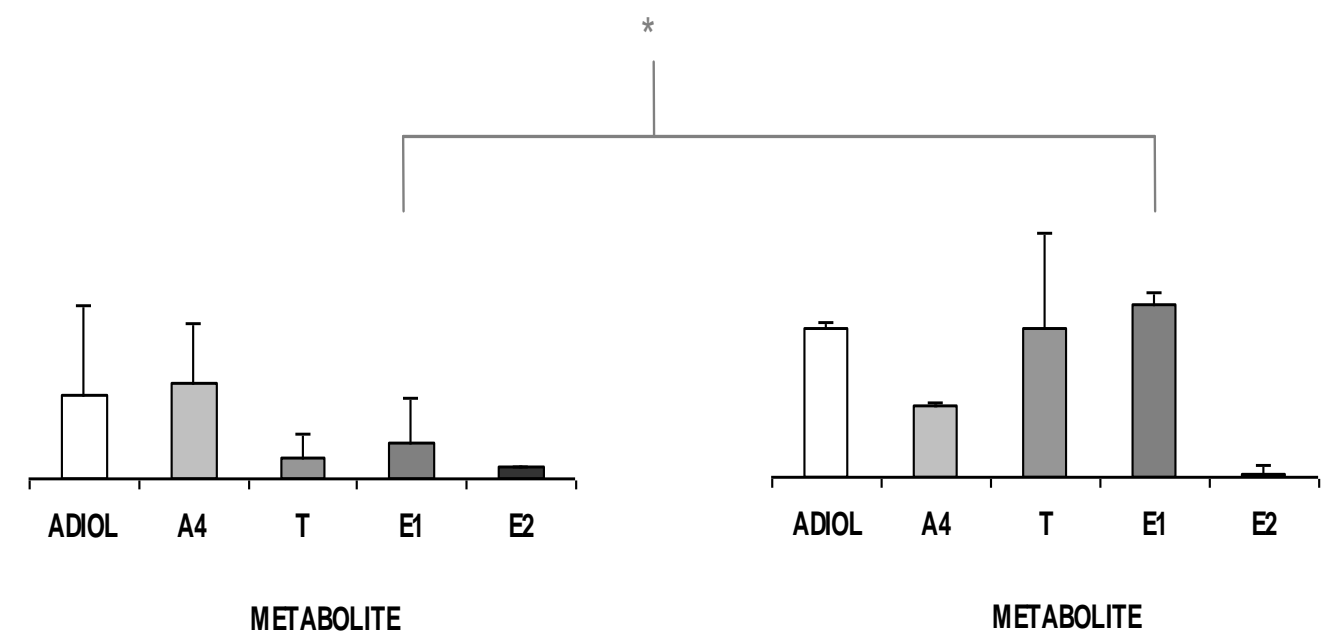

(B) 